\title{
HUMANIDADES DIGITAIS: IMPACTOS DA INOVAÇÃO TECNOLÓGICA NA ARQUIVOLOGIA E DOCUMENTAÇÃO
}

\begin{abstract}
Resumo: A presente pesquisa é fruto do desenvolvimento de um estudo interdisciplinar que buscou elucidar impactos encontrados no processo de consulta e organização do documento arquivístico de idade permanente, digitalizado. Buscamos analisar formas de organização da documentação de idade permanente desenvolvidas na Espanha, em relação às unidades de informação brasileiras. Os processos de estudo na Espanha, como aplicados no Brasil, objetivaram a busca de contrastes e aproximações em relação aos procedimentos entre as duas tradições acadêmicas. A partir da perspectiva dos estudos das Humanidades Digitais, um dos principais objetivos do trabalho foi sistematizar questões debatidas no campo da digitalização de acervos permanentes e colaborar com novas reflexões para ambas as principais áreas enfocadas: Arquivologia e Documentação.
\end{abstract}

Palavras-chave: Humanidades Digitais. Arquivologia. Documentação. Digitalização de acervos.

\author{
Hercules Pimenta Santos \\ Doutor em Ciência da Informação, PPGCI- \\ ECI/UFMG \\ Universidade Federal de Minas Gerais \\ Departamento de Organização e \\ Tratamento da Informação \\ herculessantos.ufmg@gmail.com
}

\section{DIGITAL HUMANITIES: IMPACTS OF TECHNOLOGICAL INNOVATION IN ARCHIVOLOGY AND DOCUMENTATION}

\begin{abstract}
The present research is the result of the development of an interdisciplinary study that sought to elucidate the impacts found in the process of consultation and organization of the archival document of permanent age, digitized. We sought to analyze ways of organizing the documentation of permanent age developed in Spain, in relation to the Brazilian information units. The study processes in Spain, as applied in Brazil, aimed the search for contrasts and approximations in relation to the procedures between the two academic traditions. From the perspective of Digital Humanities studies, one of the main objectives of the work was to systematize issues debated in the field of the digitization of permanent collections and to collaborate with new reflections for both main focus areas: Archival and Documentation.
\end{abstract}

Keywords: Digital Humanities. Archivology. Documentation. Digitization of collections. 


\section{INTRODUÇÃO}

O presente texto deriva da pesquisa de doutorado concluída no ano de 2018: Impactos provenientes da Redocumentarização de acervos permanentes na pesquisa histórica. Esta compreendeu um estudo interdisciplinar que buscou elucidar impactos encontrados no processo de consulta e organização do documento arquivístico de idade permanente digitalizado. Procuramos analisar formas de organização da documentação de idade permanente desenvolvidas na Espanha, em relação às unidades de informação brasileiras.

$\mathrm{Na}$ tese, procuramos compreender a incidência da virtualização das fontes de informação nos fazeres historiográfico e arquivístico. Um dos principais objetivos da pesquisa foi sistematizar as questões debatidas no campo da virtualização dos acervos arquivísticos e colaborar com novas reflexões para ambas as principais áreas enfocadas: Arquivologia e História.

Preocupava-nos o fato de que, ocasionalmente, as inovações tecnológicas podem apresentar propostas alçadas rumo a expectativas de futuro que venham a desconsiderar alguns procedimentos tradicionais. Buscamos confirmar, com a pesquisa, que os acervos digitalizados trouxeram novos significados para a pesquisa histórica. Mas também qual o impacto que essa virtualização gerava para os profissionais que organizam a documentação de arquivo de idade permanente.

Nosso esforço de reflexão teórico se circunscreveu no recente campo de investigação, denominado por Humanidades Digitais (HD) ${ }^{1}$, procurando entender o impacto das inovações tecnológicas nas tradições historiográfica e arquivística, considerando ambas as áreas como passíveis de serem operadas dentro do universo digital.

Buscamos compreender como os procedimentos de disponibilização documental virtual vêm impactando o acesso às fontes de pesquisa, na perspectiva das necessidades metodológicas dos historiadores. O objetivo final foi ampliar o entendimento sobre novos conceitos, como o de Redocumentarização, e os impactos do presente alargamento da

\footnotetext{
${ }^{1}$ Humanidades Digitais (HD), é “um campo de estudo, pesquisa, ensino e inovação preocupados com a interseção da computação com as disciplinas da área de humanas. É por natureza metodologicamente interdisciplinar em sua abrangência. Tratando de pesquisa, análise, síntese e disponibilização da informação em formato eletrônico. Estuda como estes elementos afetem grande parte das disciplinas em que se encontram presentes e o que estas disciplinas têm a contribuir para o nosso conhecimento em formato computacional" (KIRSCHENBAUM, 2010, p. 2). 
circulação de informações e do acesso aos documentos, com foco estabelecido, principalmente, no documento de arquivo, via meio virtual.

Nos interessou saber se os princípios básicos da organização documental arquivística permaneciam, independentemente da forma de disponibilização do corpo documental, a partir das novas e diversas formas dessa organização que têm sido possibilitadas pelo meio virtual. No presente artigo, focaremos nos entendimentos obtidos em relação aos procedimentos da organização arquivística.

Aqui, o leitor encontrará resultados parciais obtidos a partir de uma pesquisa qualitativa com amostra não probabilística e intencional. O objetivo de nossa consulta foi identificar a opinião de profissionais que possuem o documento arquivístico como objeto de pesquisas e trabalho. Buscamos elucidar dificuldades e vantagens encontradas no processo de consulta, organização e tratamento do documento digitalizado que adquiriu a fase permanente de preservação.

O pano de fundo da discussão foi o documento digitalizado, mas em alguns momentos nos permitimos uma aproximação das discussões com os documentos eletrônicos de maneira geral, inclusive sobre os nativos digitais. O perfil dos entrevistados, identificados pelas siglas AB01 a AB07 ${ }^{2}$ e DE01 a DE07 $7^{3}$, foi considerado de vital importância para a pesquisa, por entendermos que somente quem atua nessa prática diariamente poderia nos informar com propriedade a respeito do assunto pautado. Foram apresentadas informações as mais variadas sobre o tema, advindas do total dos 14 entrevistados. De tal modo, no tema "Digitalização e virtualização do documento de acervo permanente", buscamos conhecer as mudanças que fossem consideradas positivas e / ou negativas.

\section{DIGITALIZAÇÃO E VIRTUALIZAÇÃO DO DOCUMENTO DE ACERVO PERMANENTE: PREOCUPAÇÕES DOS PROFISSIONAIS BRASILEIROS E ESPANHÓIS}

O resultado dessa reflexão foi que $100 \%$ dos entrevistados brasileiros relataram a existência de considerações acerca de ganhos e também a geração de problemas provenientes do processo de digitalização. No caso dos entrevistados espanhóis, 100\% declararam haver

\footnotetext{
${ }^{2}$ AB na sigla escolhida significa Arquivista Brasileiro.

${ }^{3}$ DE na sigla escolhida significa Documentalista Espanhol.

PontodeAcesso, Salvador, v.13, n.1, p.65-86, abr. 2019 www.pontodeacesso.ici.ufba.br
} 
vantagens no processo, com quatro desses profissionais afirmando compreenderem a existência de problemas. Constatamos o surgimento de preocupações relativas aos documentos eletrônicos com relação aos temas de sua organização, preservação e disponibilização para acesso, quando comparado com o tratamento e a disponibilização para acesso dos acervos físicos.

\subsection{A IMPORTÂNCIA DE UMA DESCRIÇÃO ADEQUADA DOS ACERVOS DIGITALIZADOS E O PAPEL DO ARQUIVISTA}

Alguns entrevistados brasileiros demonstraram compreender a concepção de digitalização dos documentos, na Arquivologia, como uma questão meramente técnica e complementar. Do ponto de vista do ofício e do desenvolvimento das práticas arquivísticas, os profissionais entrevistados atribuíram fundamental importância na contínua perseguição dos mesmos objetivos empregados no tratamento tradicional, como manter os acervos arquivísticos com seu vínculo orgânico. $\mathrm{O}$ entrevistado $\mathrm{AB} 01$ considerou que "inclusive, é isto que faz com que continuemos tendo a mesma denominação", ou seja, que a organização de acervos documentais digitalizados esteja nas mãos do profissional arquivista, fato que se deve à manutenção dos princípios organizacionais próprios desse profisssional.

Essa indissociável manutenção dos princípios tradicionais, para $\mathrm{AB} 01$, foi e é importante, além de propiciar novos olhares sobre o tradicional: "porque quando se buscou esta solução, retomamos coisas muito antigas, procedimentos, por exemplo, medievais, como estudar a diplomática, a qual foi revista para enfrentar este desafio tão contemporâneo, que é o documento no meio eletrônico".

Diante de todo um trabalho que precisa ser feito pelo profissional da informação, além do mais recente, que é o de disponibilizar acervos on-line, também é necessário pensar no papel do profissional arquivista. Frente às possibilidades digitais, notamos que a importância desse profissional cresceu, em função da necessidade de um maior cuidado na organização do grande montante de informação e documentação que passamos a contar. Sua função não estará restrita a guardar e dar acesso ao que seja considerado relevante.

Para AB07, por exemplo, "não faz sentido guardar o que não tem valor [...] a digitalização amplia o nosso papel, por mais que algumas pessoas digam que com a digitalização não haverá o arquivista". Para AB07, a digitalização insere ainda mais o arquivista no mercado de trabalho, imputando-lhe mais responsabilidades, "porque uma coisa é o 
documento aqui comigo, outra coisa é como e quando este vai parar lá do outro lado do mundo" e, "cabe ao arquivista desenvolver consciência desta amplitude". Assim, diferente do que seria o entendimento de alguns profissionais, para AB07, a digitalização não excluirá esse profissional, e, sim, incluí-los, agregando ainda mais responsabilidades.

O surgimento de procedimentos considerados mais delicados, quando contraposto ao tratamento físico de acervos arquivísticos, emanou de considerações como "esse movimento de disponibilização do acervo em meio digital não pode ser analisado sem uma discussão sobre a qualificação da descrição". O que AB04 relatou estar presenciando é: "em várias instituições, uma digitalização sem a descrição adequada". A preocupação com a descrição adequada dos acervos apareceu com grande destaque nos relatos dos entrevistados AB01, AB04, AB06 e AB07, além dos entrevistados espanhóis DE03, DE06 e DE07.

Para o entrevistado AB06, quando se disponibiliza um conjunto de documentos online, teoricamente, trata-se de um momento muito específico dessa documentação, pois esta não se encontra mais no âmbito da gestão do dia a dia das instituições. Para a comunidade arquivística, a partir do momento que ela é a responsável por organizar e disponibilizar para o usuário a documentação, acarretaria em alterações na maneira de pensar a própria disponibilização. Conforme AB06, "se tornou muito importante organizar e descrever corretamente esses fundos".

Esses relatos, conjugados com a percepção do conjunto das entrevistas, confirma-nos que a qualificação do acesso do usuário aos fundos e coleções não pode acontecer pela mera digitalização ou disponibilização do acervo digitalizado. A aplicação dos processos de organização próprios da Arquivologia é primordial e permitirá ao pesquisador delinear melhor a sua pesquisa.

Como observado na fala de AB07, o processo de digitalização de acervos arquivísticos traria um ganho duplo quando bem descrito, pois "temos ganho de tempo no nosso trabalho". Apesar de considerar que não é objetivo da digitalização, "ganhamos tempo apesar de, no início, gastarmos mais tempo para organizar", se referindo à possibilidade de o usuário se auto servir daquilo que procura.

Para AB04, no caso de instituições com diversas outras questões importantes para se ocupar, entre elas, garantir condições para o recolhimento dos acervos, a digitalização deve ser considerada uma alternativa para melhorar o atendimento ao usuário. E “a partir daquilo que é 
um acervo mais quantificado, um bom trabalho de planejamento institucional tem que abarcar isto [a descrição adequada]".

Esse trabalho de descrição é considerado um grande desafio para AB06: "você deve se colocar no lugar do usuário, pois a sua descrição tem de ser ágil [...] e, na minha opinião, isto assusta muito o profissional da informação". Para AB06, o conjunto de documentos, quando chega à mão do usuário, precisa oferecer elementos para que possa refletir o conjunto. AB06 pondera que "se eu não conseguir transmitir na minha descrição a organização desse contexto, de maneira adequada, o usuário vai ter problemas", referindo-se à contextualização dos documentos.

O documento virtualizado precisa estar contextualizado. É preciso ser relacionado com outros documentos, pois a Arquivologia não trabalha com peças únicas, um documento geralmente está relacionado a outro(s). Ao se digitalizar, pode-se acabar fragmentando sua organicidade. O profissional que está dentro da instituição de guarda, geralmente, entende a importância e o significado dos conjuntos documentais e precisa transmitir essa percepção para o consulente. O documento não possui informação no sentido estrito do termo, a informação não é apenas aquela que está registrada no documento: este possui informações que estão a sua volta, e isso não pode ser desprezado em relação ao documento arquivístico.

\subsection{ACERVOS DIGITALIZADOS, ACERVOS NECESSARIAMENTE DUPLICADOS}

O arquivo, ao duplicar digitalmente parte dos seus acervos, vive a consequência de um desafio maior. Nesses termos, dizemos relativamente duplicados, pois o acervo e os procedimentos serão duplicados frente à impossibilidade metodológica de descartar os documentos originais que foram digitalizados. Pois, entendemos e defendemos, que serão os originais físicos que vão conferir autenticidade e fidedignidade à imagem digital.

Surgiu a responsabilidade de ser capaz de manter um site confiável, no qual se disponibilizem fundos arquivísticos on-line, ininterruptamente. Os pesquisadores agora vêm de todos os lugares possíveis: "[o pesquisador] pode estar no Japão desenvolvendo uma pesquisa, mas não pensará nos arquivos como uma instituição em sua forma tradicional” (AB02). Aqui, o entrevistado, se referiu à responsabilidade de não interferir no fluxo das pesquisas, preservar os acervos físicos e ser capaz de gerir um acervo virtualizado. Para AB02, "essa tecnologia não poderá superar a preservação do acervo físico, do documento de arquivo", referindo-se à 
manutenção do princípio da autenticidade, entendendo que este princípio será garantido diante da consulta ao objeto original, o qual fornecerá as características que demonstram não ter esse objeto sofrido modificações.

Essa importante questão, que é a preservação dos documentos originais, apareceu recorrentemente na fala de grande parte dos entrevistados brasileiros e espanhóis. Para esses profissionais, é primordial que no mundo da tecnologia digital os princípios arquivísticos sejam preservados. O documento arquivístico é prova de algo, tem poder de comprovação, e esse poder ocorre em função de uma série de características que garantem a sua autenticidade. É preciso garantir essas mesmas propriedades do documento físico para a representação eletrônica. Os entrevistados, assim como nós, consideram impensável a substituição do documento físico pelo seu espelho eletrônico.

Com relação a essa mesma preocupação - a preservação do documento original AB02 considera que teremos novos problemas se não pensarmos de forma muito detida e preocupada na continuidade da manutenção da forma como o documento foi constituído: "penso que corremos o risco de entender que se está modernizando, neste sentido é modernizar mesmo, mas por outro lado podemos descuidar de algo que é preponderante: a manutenção da fonte original".

AB07, que atuou de forma prática na digitalização de documentos públicos, disponibilizando-os via Internet, relatou que "era muito claro para nós que o objetivo da digitalização não era substituir o processo de organização e nem substituir os documentos originais". AB07 complementou a questão, referente à duplicação do acervo e a indissociável preservação dos originais, em tom de desabafo, dizendo não entender como alguns profissionais "podem pensar que a digitalização vai substituir o documento original, isto não faz nenhum sentido". Junto a esse relato, AB07 afirmou conhecer profissionais da Arquivologia que entendem, concordam e defendem que haveria a possibilidade do descarte dos originais diante da possibilidade da digitalização. Note-se que no documento do CONARQ (2010, p. 04), sobre as recomendações para digitalização de documentos arquivísticos permanentes, encontra-se informado que, "as ações de digitalização não devem ser realizadas em detrimento das ações de conservação convencional dos acervos custodiados por instituições arquivísticas, por serem inalienáveis e imprescritíveis, conforme preconiza o artigo $10^{\circ}$ da Lei Federal no 8.159/1991”. 


\subsection{A PREOCUPAÇÃO COM A VULNERABILIDADE DOS ACERVOS DIGITALIZADOS}

AB03 entende como preocupante a facilidade com que essa tecnologia apresenta fragilidades, pois "o documento que está sendo digitalizado leva com ele os problemas do nosso dia a dia, frente às tecnologias". São problemas relativos ao direito autoral, intelectual, direito à privacidade e à própria obsolescência. Apesar de no início de suas considerações AB03 ter apontado grandes benefícios advindos do processo de digitalização dos documentos, ficou claro que esse entrevistado considera que a mudança mais substancial foi a geração de novos problemas que ainda precisam ser constantemente revistos. Para esse profissional, a forma maior de impacto estaria na questão da instabilidade do suporte e da tecnologia, ou na manutenção delicada, própria dos documentos virtualizados.

AB07 falou sobre valores: "a manutenção desses documentos digitais é cara, porque você tem de estar, de tempo em tempo, migrando de mídia, atualizando software, formatos digitais, etc”. Essa migração, há muito, é alvo de preocupações da comunidade arquivística. O CONARQ, em razão disso, criou uma Câmara Técnica de Documentos Eletrônicos. As Resoluções 39 e 43 desse órgão traçam a política de preservação digital brasileira, determinando “diretrizes para a implementação de repositórios arquivísticos digitais confiáveis para o arquivamento e manutenção de documentos arquivísticos digitais em suas fases corrente, intermediária e permanente, dos órgãos e entidades integrantes do Sistema Nacional de Arquivos - SINAR” (CONARQ, 2014).

No RDC-Arq ${ }^{4}$, (Repositório Digital Confiável), também são explicados em publicação técnica sobre sua implantação, o que implica na montagem de infraestrutura tecnológica de custo elevado. Abrimos aqui um parêntese para informar que, entendemos que esse alto custo, como citado por alguns entrevistados, existiria diante da estrutura tecnológica que é necessária. Para os pesquisadores espanhóis Cruz Mundet e Díez Carrera (2015), o cálculo dos custos seria uma das fraquezas mais importantes do gerenciamento e preservação digital. Embora seja uma atividade recente, ainda estaríamos longe de ter contraído um consenso e um compromisso geral

\footnotetext{
${ }^{4}$ Disponível em: <http://www.conarq.gov.br/images/publicacoes_textos/diretrizes_rdc_arq.pdf $>$. PontodeAcesso, Salvador, v. 13 , n.1, p.65-86, abr. 2019 www.pontodeacesso.ici.ufba.br
} 
sobre sua necessidade, além da comunidade especificamente envolvida em sua prática. Existiria uma convicção ampla e errônea de que os valores estariam centrados na natureza tecnológica e, por conseguinte, concentrados no hardware, cada vez mais barato e em software, que é incorporado aos sistemas de gerenciamento.

O documento do CONARQ (2010) orienta os gestores e os demais profissionais envolvidos nas instituições de arquivo a fazerem planejamento antecipado dos custos de implantar um projeto de digitalização. Alerta que tal processo exige, primeiramente, uma previsão orçamentária e financeira capaz de garantir a obtenção, atualização e manutenção de versões de software e hardware compatíveis com as demandas atualizadas constantemente. Além disso, é importante adotar requisitos técnicos que garantam preservar e manter a acessibilidade aos acervos dos documentos eletrônicos gerados em curto, médio e longo prazos.

Compreendemos que tais custos são relativos, diante dos benefícios que podem ser oferecidos. Dessa maneira, não seria o caso de comparar com o valor de manutenção dos arquivos físicos. Porque o uso do espaço físico continuará a ser contabilizado e a ele acrescentada a duplicação com o acervo virtualizado, devido ao material digitalizado, o que demandará a adição dos valores desse processo ao orçamento do arquivo físico que disponibiliza e preserva parte do seu acervo também virtualmente.

Quando se ouve falar que a guarda e preservação de documentos de forma digital teria menores custos financeiros que os tradicionalmente em suporte papel, entendemos que isso seria real no caso da produção nato digital de documentos e sua consequente preservação eletrônica. $\mathrm{O}$ documento criado digitalmente e que cumpre sua função por meio do meio eletrônico é o documento original. Sua impressão em papel é, na verdade, uma cópia materializada em um suporte físico. Dessa forma, não existe duplicação de acervos, como apontamos ser uma realidade no caso da digitalização dos acervos clássicos. De qualquer maneira, os custos para a manutenção de acervos digitais e digitalizados envolvem gastos (o CONARQ recomenda softwares livres), infraestrutura informática e de rede, além do monitoramento permanente de toda essa frágil e delicada tecnologia.

AB06 considera que "muitos de nós não estamos preparados para lidar com essa tecnologia e aqueles que estão preparados, muitas vezes, deixam um pouco de lado os pormenores da descrição documental". AB06 buscou asseverar, com esse relato, que, frequentemente, os profissionais mais bem preparados tecnicamente, geralmente, estão menos preparados teoricamente, acarretando em falhas na aplicação dos procedimentos arquivísticos. PontodeAcesso, Salvador, v.13, n.1, p.65-86, abr. 2019 www.pontodeacesso.ici.ufba.br 
Em resumo, as "vulnerabilidades" foram lacunas provenientes de vários fatores. Podemos citar sistemas informáticos desatualizados ou mal desenvolvidos e os sujeitos malintencionados que os invadem para acessar os conteúdos armazenados. Também, softwares mal instalados ou mal configurados. As mídias de armazenamento, todas muito frágeis, precisam de atenção redobrada para que as informações não sejam danificadas. A chamada redundância dos dados gravados nas mídias precisa ser adotada e em locais distintos geograficamente, como forma de prevenção e amenização em caso de acidentes.

Além da fragilidade própria desses equipamentos, existe a chamada obsolescência programada, uma prática de mercado na qual os produtos são projetados de forma que sua durabilidade, ou funcionamento útil, aconteça em um período determinado e reduzido. Isto acarreta a necessária substituição desse material da parte de seus consumidores, periodicamente, aumentando a lucratividade das empresas.

\subsection{A PREOCUPAÇÃO COM QUESTÕES POLÍTICAS}

A memória social não é capaz de arquivar tudo. Lembra-se de algumas coisas, esquecese muitas outras e apenas uma amostra de todos os registros se tornará arquivo. Na seleção de registros, como observado por Nesmith (1998), dispô-los em um "pedestal" altera o seu contexto, determina novos significados para o registro do que restou para a constituição de séries e fundos. De tal modo, essa seleção vai indicar as narrativas possíveis.

De forma transversal, a partir desta pesquisa, foi possível inferirmos, emergindo das falas de parte dos entrevistados, questões políticas, inerentes ao trato com os acervos. São questões que insurgiram de maneira mais explícita dos entrevistados AB01, AB02 e AB04 e de forma indireta dos relatos de entrevistados espanhóis das áreas de história e documentação. A percepção que têm os especialistas em arquivos é que, aproximadamente, $5 \%$ seja a quantidade de documentos que são digitalizados e disponibilizados virtualmente pelos arquivos, apesar de essa informação não ser confirmada oficialmente. Ainda que esse montante venha a significar milhões de documentos, quando se está falando do ponto de vista da prática arquivística, a digitalização tem passado por um processo de seleção, de acordo com demandas culturais e condicionada pela disponibilidade financeira. 
Desconhecemos que algum arquivo no mundo, até o momento, disponibilizou todo o seu acervo on-line, provavelmente por ser algo caro, trabalhoso, envolver a questão da autenticidade e os muitos recursos financeiros que carecerão de ser mobilizados. Assim, o que está indo para a Internet? AB01 nos informa que uma instituição é composta por uma infinidade de fundos de documentos e, a este respeito, enfatiza: “O processo de digitalização, e vou numa perspectiva das instituições de arquivo, é muito complicado. Se dá, principalmente, por meio de leis de incentivos culturais e essas leis nos fazem, ou relativamente nos obrigam, a escolher determinados fundos e não outros".

Percebemos, aqui, um tema que mereceria uma discussão mais aprofundada. Seria importante entender as políticas no âmbito das instituições sendo levadas a privilegiar o que, como e quando devem ou podem digitalizar. Esse é um fator que perpassa o tema, mas se acredita que, de forma um pouco velada, logo, nada discutido.

AB04 nos relatou que nas instituições nas quais trabalhou "essa discussão sobre o que digitalizar e quando digitalizar foi abordada em dado momento, porém não foi aprofundada". Pois, de forma mais emergencial, “foi preciso definir: do que é que o nosso usuário precisa?". Tal questão acabou sendo sanada, sem muito profundamente se refletir, determinando o privilégio dos fundos fisicamente mais consultados.

Para AB02, no presente momento, "temos que pensar como conviver ou talvez como vamos caminhar nessa transição do que se privilegia e o que não se privilegia. São questões que não são apenas de caráter coordenativo". Esse entrevistado considera ainda que, "às vezes, nos debatemos muito com essa dificuldade de uma definição do que a instituição privilegiará, inclusive, em função da rotatividade das pessoas [profissionais de arquivo] e o que cada uma delas considera interessante".

Deduzimos que tal discussão merece ser trabalhada e analisada com mais afinco, observando-a como um problema. Percebemos que se acaba reproduzindo conhecimento a partir do que é frequentemente acessado. Esse é um problema que precisa ser questionado. Pois, por exemplo, ao se disponibilizar virtualmente os documentos mais visitados fisicamente, pode ser que esse procedimento venha a limitar o surgimento de novas análises e novas perspectivas de pesquisas históricas. É notório que muitos historiadores insurgem novas discussões pelo contato com arquivos e acervos anteriormente não estudados.

Cremos estar diante de uma demanda para se pensar no que tem sido privilegiado e na possibilidade de uma digitalização total dos acervos, por mais difícil que isso soe nos tempos PontodeAcesso, Salvador, v.13, n.1, p.65-86, abr. 2019 www.pontodeacesso.ici.ufba.br 
atuais. Mas o problema seria amenizado apenas dessa forma? Nessa seara é como se o arquivo estivesse fazendo o seu importante papel de preservação documental, mas, por outro lado, novas pesquisas seriam estimuladas se os documentos menos buscados fossem colocados à disposição. A forma mais primária de se alertar para documentos pouco ou nada interpretados é trazendo-os à evidência.

Nesse quadro, Ketelaar (2001) defende que fundos de arquivos, documentos de arquivo, instituições arquivísticas e sistemas de arquivamento contêm narrativas tácitas que precisam ser desconstruídas, a fim de compreender os significados dos próprios arquivos. Para esse pesquisador, abundantes narrativas tácitas estão ocultas na categorização e indexação dos documentos. $\mathrm{O}$ arquivamento envolve selecionar o que deve e o que não deve ser preservado para ser disponibilizado.

Ketelaar (2001), entendendo que o que se aplica na manutenção de registros em organizações, também se aplica aos arquivos como uma instituição social, defende que contextos sociais, culturais, políticos, econômicos e religiosos determinam as narrativas tácitas de um arquivo. Ketelaar buscou chamar a atenção de que tais contextos deveriam ser mais transparentes.

\section{IMPACTOS DO PROCESSO DE DIGITALIZAÇÃO DE ACERVOS NA PRÁTICA ARQUIVÍSTICA E DOCUMENTAL}

\subsection{IMPACTOS CLASSIFICADOS COMO POSITIVOS}

Avaliando o que surgiu das falas dos entrevistados, apostamos em fazer uma síntese, do que analiticamente classificamos como impactos positivos da digitalização de documentos arquivísticos para os profissionais que atuam nessa área. Como exemplificação, apresentamos algumas falas, destacando o fato de que o elemento que mais adveio dos entrevistados espanhóis foi sobre preservação e conservação:

É uma conquista social em relação às massas de dados. Significa um grande avanço para a população. Você pode consultar de madrugada de qualquer parte do mundo, fora do seu horário de funcionamento. Isto, hoje, não é mais visto com um tipo de preconceito, muito pelo contrário, tem sido muito bem-visto como algo necessário. E, por outro lado, cada vez mais, você tem arquivistas trabalhando em conjunto para adequar essa tecnologia (AB01).

PontodeAcesso, Salvador, v.13, n.1, p.65-86, abr. 2019

www.pontodeacesso.ici.ufba.br 
Apresenta um novo significado, do ponto de vista estrutural, do ponto de vista social. Um novo significado porque permite agregar um número maior de pessoas em torno do que foi preservado da história e da memória. Temos a possibilidade de uma guarda documental de forma mais efetiva, muito mais protegida, o que considero importante do ponto de vista do processo de preservação e democratização do acesso (AB02).

Todos nós podemos ter acesso a documentos que não podem estar disponíveis para acesso para qualquer pessoa, em função de sua fragilidade. Assim, podemos preservá-lo melhor e permitir que muitas outras pessoas tenham acesso ao seu conteúdo informacional. Mas, se entendemos que este documento, como um objeto, tem valores materiais, podemos ir até o arquivo para consultá-lo (DE03).

Como arquivista, acredito que o mais importante da digitalização dos documentos de acervo é a conservação [...] temos aí uma cópia de segurança destes materiais originais, ainda que a digitalização não seja garantia de conservação a longo prazo [...] Do ponto de vista do profissional de arquivo, penso que o arquivo também ganhou muito com isto por permitir uma difusão maior do que é uma instituição de arquivo e o que se pode encontrar em um arquivo, estas vantagens são fundamentais (DE05).

Apesar de apresentarem vários pontos positivos, de forma geral, os profissionais da informação consideram que se tal processo ainda não está melhor adequado às demandas de consulta, seria porque o diálogo com o profissional da tecnologia ainda não está "encaixado", usando aqui o termo empregado pelo entrevistado AB01. Mas AB01 afirma que já melhorou muito: "não é a mesma coisa que era há 10 anos".

Este é um fator presente nos processos de diálogo entre a comunidade computacional, que tem dificuldade de entender o que é demandado pelo grupo do patrimônio cultural e viceversa. O trabalho em conjunto de pessoas com formação em Museologia, História das Artes, Arqueologia, História Natural, Física, Ciência da Computação e Filosofia - não se esgotando nessas áreas -, buscando chegar a um termo funcional entre a complexidade da organização dos conceitos e a complexidade da descrição de processos, sempre demanda muito estudo, muito diálogo, muita determinação em tentar entender alguns fundamentos de áreas muito distintas como Exatas, Humanas e Sociais (SANTOS, 2016).

Retomando os relatos, os profissionais da informação entendem a digitalização e disponibilização remota dos acervos arquivísticos como uma forma de contarmos com muito mais fontes de informação de valor secundário disponíveis. Pode-se contar com mais acesso aos dados documentais em função dos sistemas de recuperação da informação. Nesse sentido, elucidamos com o relato de DE06, para quem esse processo de digitalização permite a melhora da difusão dos conteúdos documentais “de uma forma magnífica”. Além disso, permite que os 
próprios usuários façam pesquisas eletrônicas, adquirindo uma certa autonomia. DE06 também chamou a atenção para uma melhor conservação de documentos "muito delicados, como códices antigos, que são muito difíceis de conservar, além de fotografias”. Todos estes fatores "melhoram consideravelmente a possibilidade de divulgação desses documentos" (DE06).

DE07 considera que "a automação e digitalização de arquivos é a chave [...] Esses processos constituem a mudança de paradigma nos arquivos nos últimos 10 anos".

Do meu ponto de vista, o de professor de Ciências da Documentação, posso dizer que os sistemas de gerenciamento de arquivos são a base para o melhor uso da documentação permanente. Isso não se limita apenas à digitalização de documentos, também à descrição, transcrição, identificação de autoridades, alocação de metadados, o que favorecerá a recuperação (DE07).

AB05 relatou uma de suas experiências práticas com a pesquisa histórica, considerando-a de extrema utilidade e facilitadora do seu processo de investigação. Trata-se do sistema do Centro de Pesquisa e Documentação de História Contemporânea do Brasil (CPDOC), da Escola de Ciências Sociais da Fundação Getúlio Vargas (FGV) ${ }^{5}$. Esse banco de dados possui arquivos pessoais de diversos políticos, como o ex-presidente Getúlio Vargas e Gustavo Capanema ${ }^{6}$. Um acervo que possui projetos de História oral, além de documentação dita tradicional. Por meio de um cadastro, podem-se fazer pesquisas e salvar os documentos em uma pasta virtual constituindo, assim, o acervo que interessa ao pesquisador. Conta-se, ainda, com uma espécie de cesta virtual, que permite atribuir comentários em cada documento adicionado. De acordo com o entrevistado, os instrumentos de pesquisa possuíam outra característica. Hoje, conta-se com novas e variadas formas de indexação e recuperação da informação, representando novidades a partir do digital.

No tocante à conservação, os documentos, ao serem digitalizados, são fisicamente prejudicados, pois receberão uma luz forte e intensa, que é prejudicial a sua estrutura, além de constituir-se em um dano irreversível e acumulativo. Por outro lado, quando se movimentam esses documentos, retirando-os de suas caixas por inúmeras vezes a cada consulta, isto também acarretará em danos. Como relatou DE04, "há algo que acredito que já foi superado, mas quando começamos com a digitalização, recomendava-se a microfilmagem dos documentos, principalmente porque a microfilmagem requer apenas uma lente".

\footnotetext{
${ }^{5}$ Disponível em: $<$ http://cpdoc.fgv.br/>.

${ }^{6}$ Ex-ministro da educação brasileira, do período de 1937 a 1945. 
Desse cuidadoso processo entendemos ter, ao final, a digitalização proporcionando algo importante e complementar em relação a uma preservação mais longeva dos acervos físicos. Uma vez digitalizados, não será necessário manipular frequentemente os originais. Uma vantagem visível da digitalização estará na grande redução da necessidade do manuseio desses originais. O usuário terá a possibilidade de fazer pesquisas prévias, seja no arquivo, seja remotamente, visualizando o que de fato lhe vai interessar. Com isso, poderá ter certeza de que determinado documento, ou conjunto, contemplará o que de fato sua pesquisa demanda, sem manipular documentos que não lhe serão úteis.

Com uma consulta prévia via representação digitalizada, o usuário pode solicitar nos arquivos o original específico, sem necessitar manusear os demais documentos de um conjunto, códice ou dossiê, por exemplo. Mas, alertamos aqui, destacando que esse ato de solicitar um documento original físico não é uma opção estabelecida ou oferecida em todos os arquivos que possuem parte de seus acervos digitalizados. Tais locais justificam que, uma vez disponibilizado virtualmente, seja de forma local ou remota, o acesso ao original não será mais permitido - de acordo com as diretrizes que foram estabelecidas pela instituição. Essa prática, previamente observada por esta pesquisa também foi condenada, mais especificamente, pelos entrevistados DE03, DE05 e DE06. No caso dos profissionais brasileiros: AB01, AB05 e AB07. Este último, discorda totalmente dessa restrição e considera que,

[...] não é pelo fato de digitalizar um acervo que não se vai dar mais acesso aos originais, para mim nem faz sentido isto. E se o acervo não está devidamente organizado e o consulente quer fazer uma pesquisa, temos de entregar tudo para este procurar, até encontrar, o que precisa [...] acarretando no manuseio relativamente desnecessário de todo o conjunto documental (AB07).

Em suma, os profissionais entrevistados consideram como fator positivo a conquista social, compreendendo ser um grande avanço para a população em função da ampliação da democratização do acesso a essa documentação. Para DE04, dessa maneira, temos a possibilidade de melhor consulta a documentos primários. Temos "a possibilidade da comparação de textos e a tradução de escrituras, por meio de ferramentas de $\mathrm{OCR}^{7}$. Tudo isto

\footnotetext{
${ }^{7}$ Tecnologia de digitalização e conversão de documentos textuais para formato digital, usando um scanner (ou uma câmera digital) e o software de reconhecimento óptico de caracteres (OCR). Esse processo, ao mesmo tempo que digitaliza o conteúdo textual, converte-o em texto digital editável. 
me parece um passo no avanço para uma ampla divulgação dos conteúdos dessa documentação" (DE04). Também se referindo à tecnologia OCR, DE05 relatou: "agora que estou trabalhando como pesquisador, não como arquivista, [vejo que] existe a possibilidade de trabalhar com documentos que por meio dos suportes digitais facilitam para a população, de modo geral, a leitura”, se referindo, nesse momento, aos documentos de séculos passados, o que dificultava um pouco a própria leitura.

Além disso, vários dos entrevistados consideram a possibilidade de um benéfico rompimento das barreiras de tempo e espaço. Pode-se consultar os acervos disponíveis na Internet por via remota de qualquer parte do mundo e fora do horário de funcionamento das instituições de guarda. Ainda, permite um número maior de pesquisadores podendo analisar o que foi preservado da História e da memória em escala global. Por exemplo, DE03 entende que uma das vantagens é que ao mesmo tempo que preservamos melhor, "podemos obter mais informações, mais rápido, e podemos disponibilizar para acesso para um número maior de pessoas" (DE03).

Em resumo, alguns entrevistados consideram a possibilidade de uma guarda documental de forma mais efetiva, muito mais protegida. Algo muito importante considerando o processo de preservação dos acervos físicos, em função da redução significativa da manipulação dos originais por aqueles que não necessitam manipulá-los. Ou seja, por parte dos pesquisadores que geralmente necessitam contato, apenas, com o conteúdo textual do documento, o que poderá ser acessado pela imagem digitalizada.

\subsection{IMPACTOS CLASSIFICADOS COMO NEGATIVOS}

Percebemos que existe grande preocupação, pelos profissionais entrevistados, especificamente os brasileiros, no sentido de conservar a organicidade dos acervos e garantir que mantenham a mesma confiabilidade que costuma ser atribuída aos acervos físicos. Da parte dos espanhóis, apenas o entrevistado DE05 falou de maneira objetiva sobre tal fator: "isto impacta no momento de organizar estes fundos documentais. Da minha experiência, afirmo que se vem fazendo uma descrição muito menos profunda dessa documentação, do que se fazia anteriormente" (DE05).

DE05, que trabalha na área de documentação há pelo menos 25 anos, disse que a dificuldade maior de lidar com a documentação levava à situação de que a descrição dos 
documentos de valor secundário fosse muito mais completa, permitindo que, quando se buscasse por um documento, o encontrássemos: "isto não está acontecendo muito recentemente, por muito que a tecnologia tenha avançado. Este é um trabalho humano que leva muitas horas e que acaba por se estar perdendo em grande parte". O entrevistado considera que, ao mesmo tempo que se fala no crescimento da difusão, estaríamos perdendo em eficácia. Para DE05, apresentando um exemplo, o Google teria acostumado as pessoas a quando fazem pesquisas eletrônicas, não valorizarem a descrição documental, pois pelo fato de encontrarem o que estão procurando, não estariam se preocupando com detalhes: "Em muitos aspectos estamos perdendo a eficácia, estamos perdendo também no momento de seleção documental, porque como é relativamente barato guardar as coisas, a tendência é que as pessoas venham guardando tudo sem que haja uma seleção criteriosa para descarte."

AB01, especificamente, ilustrou uma apreensão recorrente: "me surge uma preocupação advinda de uma outra ordem, a de que esse documento não perca o seu contexto de produção, que ele esteja bem organizado para ser acessado, que ele tenha longevidade, tenho muito medo disso". Essa consideração está amparada na fragilidade do equipamento: "esses eletrônicos [computador] não duram mais do que cinco anos". Assim, haveria uma preocupação em operar com os processos de migração exigidos constantemente por essa documentação virtualizada, no sentido de que seja possível preservar os acervos como autênticos e adequadamente organizados eletronicamente de forma correta. A mesma preocupação foi externada por DE02, que não sente segurança sobre "se as tecnologias de amanhã garantirão a existência dos documentos produzidos digitalmente ou digitalizados hoje”.

Lembrando dos custos e vulnerabilidades, AB07 alertou: "As pessoas têm a falsa ideia de que não se consome espaço e dinheiro, inclusive, com essa ideia de 'nuvem'. Pensam que a 'nuvem' não existe fisicamente, mas trata-se de um servidor em algum lugar, um espaço sendo utilizado que não é barato".

O entrevistado AB07, em suas considerações a respeito da contratação de um serviço comumente chamado de nuvem (originariamente cloud computing), destacou que esse espaço está sujeito a problemas como acesso indevido às informações: "imagina colocar documentos do órgão público que trabalho, on-line, e alguém 'hackear' esse servidor e nesses documentos fazer alterações". O entrevistado se referiu, nesse caso, à possibilidade do surgimento de problemas que poderão gerar desconforto tanto para os agentes públicos da instituição, quanto 
para várias pessoas e outras instituições ligadas àquela instituição, além de uma infinidade de outras problemáticas possíveis que o acesso mal-intencionado a esses acervos poderia gerar.

De tal modo, considerando o documento do CONARQ (2010) sobre esse assunto, entendemos que não se deveria confiar as matrizes digitais ao serviço de cloud computing. Pois, de acordo com as recomendações, os representantes digitais devem ser armazenados e gerenciados por profissionais qualificados em Tecnologia da Informação e o acesso aos documentos eletrônicos deve ser restrito a usuários credenciados. $\mathrm{O}$ armazenamento da matriz digital, proveniente do processo originário da digitalização, deve se dar em espaço protegido e desconectado dos sistemas e redes de dados que permitam o seu acesso por via remota.

O pesquisador espanhol DE04 esboçou preocupação similar à de AB07.

Para mim, a desvantagem, como em tudo - uma vez me disse um professor que tive durante a faculdade: as imagens não mentem, quem mente é quem maneja as imagens -, é a possível manipulação dos textos e o que queiram fazer com estes. Na História se diz que esta é contada pelos vencedores, assim tudo isto passa pela forma de interesse das pessoas (DE04).

Diante dessa problemática, Herencia (2012) coloca em questão o procedimento de se armazenar todos os documentos em nuvem. O autor afirma que a resposta não é única, pois dependerá de vários fatores, tais como o tipo e o tamanho da organização, o grau de confidencialidade das informações contidas nos documentos, a frequência com que eles serão acessados, entre outros fatores. Assim como inferimos das recomendações do CONARQ (2010), esse pesquisador recomenda que as instituições públicas não devam usar serviços de computação em nuvem.

Ainda, pensando metodologicamente em relação à historiografia, nos surge a dúvida de se essa disponibilidade virtual dos documentos de arquivo permanente não impactaria no cuidado ou fomentaria um descuido, no procedimento de analisar as fontes de pesquisa para além de seu conteúdo textual. Para AB05, professor do curso de Arquivologia, graduado em História, “essas mudanças trazem prejuízo para a pesquisa histórica [...] podemos estar perdendo alguma coisa". Esse entrevistado exemplificou sua proposição com o uso de um objeto frequentemente eleito como fonte de pesquisa histórica: "um quadro, por exemplo: se você tiver um sistema que mostre o quadro [digitalizado], mas não apresenta os dados contextuais, temos, então, perdas”. E considera que o quadro, tendo sido digitalizado, 
"geralmente", não fornecerá informações para além do conteúdo visual ou da sua expressão artística. Para AB05: “desta maneira, este [o quadro] estará descontextualizado".

\section{CONSIDERAÇÕES FINAIS}

Em relação à organização dessa documentação de arquivos permanentes, notamos que não houve mudanças teóricas significativas em função da digitalização dos acervos. A grande mudança estaria nas possibilidades do acesso a esse conjunto documental. A gestão ${ }^{8}$ dos documentos precisará acontecer a partir de seus métodos próprios. Os instrumentos de gestão de documentos precisam ser aplicados: plano de classificação e tabela de temporalidade. O papel do profissional da informação, nesse caso o arquivista e o documentalista, precisa continuar acontecendo no sentido de preparar os instrumentos de pesquisa.

Recorrentemente, nota-se a grande importância dada por esses entrevistados à descrição arquivística. O profissional da informação deve interpretar o conjunto documental e representá-lo para o usuário, oferecendo todo o seu potencial informativo, além de proporcionar a percepção do seu valor contextualizado. Apenas digitalizar e colocar na Internet não promoverá um acesso amplo. Promover acesso não é apenas disponibilizar, é preciso poder compreender em que contexto aquele documento está inserido e o que ele representa.

A velocidade, orquestradamente atrelada à evolução tecnológica, tornando hardware e software obsoletos, gera obstáculos à longevidade dos documentos eletrônicos, de maneira geral. Pois, além da obsolescência, também ocorrem acidentes ou defeitos nos equipamentos. Dessa maneira, recursos humanos inadequados também podem onerar bastante os projetos de implantação e manutenção dos acervos virtualizados. Deixando claro que tal fator não é exclusivo do tema aqui discutido, permeia qualquer campo profissional.

Os instrumentos de pesquisa, de maneira geral, possuíam outra característica. Os sistemas de recuperação da informação, atualmente, permitem novas e variadas formas de indexação e recuperação, representando novas possibilidades de pesquisa, como por assuntos.

\footnotetext{
${ }^{8}$ A gestão arquivística de documentos é o conjunto de procedimentos e operações técnicas referentes à produção, tramitação, uso, avaliação e arquivamento dos documentos em fase corrente e intermediária, visando sua eliminação ou recolhimento para guarda permanente (CONARQ, 2011, p. 10). 
A digitalização permite que os consulentes levem suas fontes de pesquisa para onde quiserem ao poderem possuir uma representação eletrônica do documento original.

Apesar de ser muito dito que a preservação digital seria de menor custo, diante da documentação física, por, principalmente, ocupar menos espaço, um alto custo financeiro é uma realidade nesse processo de virtualização. Esse alto custo se deve à necessidade constante de reformatação e migração para mídias atualizadas, atualização de softwares, hardwares e dos formatos digitais (tipologia de arquivos eletrônicos). Além desses fatores, a preservação física do acervo, que possui seus custos próprios, deve ser mantida.

Não há dúvida de que proceder na guarda de arquivos digitalizados exige gastos volumosos. Não se pode descuidar da segurança desse acervo, o qual demanda investimentos em pessoas qualificadas, espaço físico para manter os equipamentos que precisam estar sempre atualizados em relação a hardware e software, do consumo de energia elétrica e a sua alimentação constante, trabalho interdisciplinar, além de outros fatores. A manutenção é delicada, diante da fragilidade das mídias e equipamentos.

Em síntese, percebemos que, para os profissionais da informação entrevistados, existem problemas relativos à digitalização dos acervos arquivísticos, mais diretamente, com a fragilidade e vulnerabilidade do meio eletrônico. São fatores que ameaçam a manutenção de uma correta organização dos acervos e a longevidade do trabalho executado. $\mathrm{O}$ documento que é lido virtualmente hoje, em um formato, futuramente pode não ser reconhecido pelo software existente amanhã. Os processos de migração constantes dessa documentação eletrônica podem ameaçar a autenticidade dos documentos, além de encarecer o processo de guarda e disponibilização. Alguns entrevistados creem que o meio virtual é suscetível a problemas como, por exemplo, o acesso indevido aos acervos para nesses documentos realizarem uso ou alterações mal-intencionadas.

O receio é alimentado pela percepção de que ainda não se conseguiu resolver essas questões de forma definitiva. Essa tecnologia ainda não permitiu que as pessoas tenham acesso garantido aos documentos, diante da dependência dos aparatos tecnológicos e até mesmo da energia elétrica. Exige-se, ainda, uma manutenção delicada diante da fragilidade das mídias de armazenamento.

A disponibilidade de acesso aos documentos estará diretamente ligada à acessibilidade por meio dos equipamentos adequados, Intranet e Internet. Dificuldades encontradas para se conectar ao servidor de hospedagem dos acervos impedirão ler ou fazer o download dos 
documentos. E, saindo agora um pouco do condicionamento tecnológico, há o fato de com uma menor frequência das pessoas indo aos arquivos físicos, tal fato poderá acarretar em menor destino de verbas para as instituições de guarda. Esta última questão o leitor poderá encontrar mais amplamente discutida na tese originária do presente artigo. 


\section{REFERÊNCIAS}

CONARQ. e-ARQ Brasil: Modelo de Requisitos para Sistemas Informatizados de Gestão Arquivística de Documentos / Câmara Técnica de Documentos Eletrônicos. 1.1. Versão. - Rio de Janeiro: Arquivo Nacional, 2011.

CONARQ. Estabelece diretrizes para a implementação de repositórios arquivísticos digitais confiáveis para o arquivamento e manutenção de documentos arquivísticos digitais em suas fases corrente, intermediária e permanente, dos órgãos e entidades integrantes do Sistema Nacional de Arquivos - SINAR. Resolução no 39, de 29 de abril de 2014. Disponível em: $<$ http://www.conarq.gov.br/index.php/resolucoes-do-conarq/281-resolucao-n-39,-de-29-deabril-de-2014>. Acesso em: 04 nov. 2017.

CONARQ. Orientações para contratação de SIGAD e serviços correlatos. Orientação Técnica n. ${ }^{\circ}$ 1, Abril / 2011a. Disponível em: $<\mathrm{http}$ ://www.conarq.arquivonacional.gov.br/images/ctde/Orientacoes/Orientacao_tecnica_1.p df $>$. Acesso em: 04 nov. 2017.

CONARQ. Recomendações para Digitalização de Documentos Arquivísticos Permanentes. CONARQ, 2010.

CRUZ-MUNDET, J.R. y DÍEZ-CARRERA, C. El cálculo de costes de la preservación digital: un análisis de modelos. Anales de Documentación, 2015, vol. 18, nº 2.

HERENCIA, Ing. Juan José. Gestión de documentos electrónicos en Archivos Virtuales: Servicios en la Nube. Anais do 4th International Convention of Archivists (COINDEAR). San Bernardo (Chile), abr. 2012.

KETELAAR, Eric. Tacit Narratives: The Meanings of Archives. Archival Science 1: 131-141, 2001.

KIRSCHENBAUM, M. G. What is Digital Humanities and What's it doing in English Departments? ADE Bulletin, n. 150, 2010. Disponível em: $<$ https://mkirschenbaum.files.wordpress.com/2011/03/ade-final.pdf $>$. Acesso em: 03 out. 2019.

NESMITH, Tom. What is a Postmodern Archivist? Annual meeting of the Association of Canadian Archivists. Halifax, May 1998.

SANTOS, Hercules Pimenta dos. Modelo CIDOC CRM: interoperabilidade semântica de informações culturais. Brazilian Journal of Information Studies: Research Trends. 10:1, 2016. 